DOI 10.5216/ia.v45i3.65176

\title{
ESTUDO COMPARADO DAS POLÍTICAS DE FORMAÇÃO CONTINUADA PARA PROFESSORES: POSSÍVEIS REFLEXÕES A PARTIR DO BRASIL E DA ARGENTINA
}

\author{
Francine Cordeiro Bobato \\ PALOMA DOMINGUES FERREIRA \\ Universidade Estadual do Centro-Oeste (UNICENTRO), Irati, Paraná, Brasil
}

\begin{abstract}
RESUMO: O presente artigo teve como escopo um estudo comparado das políticas de formação continuada de professores no Brasil e na Argentina. A partir da pesquisa bibliográfica e documental, ensaiamos possíveis reflexões sobre as políticas desses países, alinhadas ou não com os postulados dos organismos internacionais. Diante dos achados da pesquisa, concluímos que ambos os países atenderam a tais postulados, adotando seus conceitos e modos de conceber a docência e o fazer pedagógico. No rol dos textos estudados, acerca da formação continuada dos professores, podemos destacar que: aparece como garantia de melhoria das aprendizagens dos alunos; há recorrência pela formação em serviço; a certificação em detrimento das reais situações de ampliação e aprofundamento de conhecimentos; os múltiplos espaços e ofertas dessa formação, especialmente pela iniciativa privada, e a ênfase no saber fazer.
\end{abstract}

Palavras-chave: Políticas de Formação Continuada de Professores. Trabalho Docente. Reformas Educacionais. Organismos Internacionais. Brasil e Argentina.

INTRODUÇÃO

\begin{abstract}
Como professores, todos nós, em algum momento, fomos chamados à 'qualificação', ora porque uma nova lei havia sido promulgada, ora porque um novo governo assumia para tudo mudar mantendo a mesmice da escola e suas mazelas, ora porque a formação inicial que tivemos era submetida a uma avaliação negativa, o que impunha que fôssemos mais bem preparados, ora porque modelos metodológicos cientificamente embasados, tornados modismos, perdiam sua hegemonia. (COLLARES; MOYSÉS; GERALDI, 1999).
\end{abstract}

O excerto acima revela diferentes motivações que justificam propostas de formação continuada, consubstanciadas pelas reformas educacionais, e que submetem professores a diferentes iniciativas sob a aba da Formação Continuada. Por certo, a década de 1990 representa um marco nas reformas educacionais impulsionadas na América Latina, fruto da necessidade de adequação "[...] à nova ordem econômica, das mudanças trazidas pela revolução tecnológica e pelos novos sistemas de informação e comunicação" (BUENO et al., 2012, p. 1). 
No bojo das reformas educacionais, seus ideais aparecem materializados basicamente nos seguintes aspectos: mudanças nos currículos, sistemas nacionais de avaliação, formação de professores, em especial a formação continuada, educação à distância e o uso das tecnologias da informação e comunicação. Contudo, seus efeitos vão muito além, pois:

[...] as tecnologias da reforma da educação não são simplesmente veículos para a mudança técnica e estrutural das organizações, mas também mecanismos para 'reformar' os professores e para mudar o que significa ser professor. Isto é, 'a formação e actualização (sic!) das capacidades e atributos do SER professor' (DEAN, 1995, p. 567). A reforma não muda apenas o que nós fazemos. Muda também quem nós somos [...] (BALL, 2002, p. 4-5).

Assim, a formação continuada de professores constitui-se um campo de tensões e disputas, em que as lutas internas, alinhadas às hierarquias presentes no campo das políticas docentes, revelam os conflitos e as "[...] relações de poder que permeiam as relações humanas nas instituições de formação de professores" (MARTINEZ, 2014, p. 55). Essas tensões e disputas, na maioria das vezes, favorecem os interesses privados. Para Bueno et al. (2012, p. 3),

A multiplicação de cursos de formação de professores de níveis, extensão e modalidades diversas é uma das ênfases das políticas correntes, as quais têm favorecido, por meio de consórcios e parcerias diversas, abertura crescente para a entrada de empresas privadas no terreno antes reservado à atuação do Estado. $\mathrm{O}$ agravamento das condições de trabalho dos professores e a qualidade insatisfatória de muitos desses programas têm acirrado o debate entre educadores e pesquisadores sobre essa questão, entre outras razões, pelo fato de que tais políticas, mais do que democratizar a educação, têm contribuído para a produção de novas hierarquias sociais.

Na realidade, as políticas postas aos professores implicam também em novas responsabilidades, reconfiguração da docência e do próprio professor, como dito por Ball (2002) anteriormente. O aligeiramento da formação inicial, que tem se reconvertido no paradigma do saber fazer em detrimento da práxis, a formação continuada colocada a serviço das fundações empresariais e as péssimas condições de trabalho precarizam e desqualificam a docência.

$\mathrm{Na}$ maioria das propostas educacionais traçadas, competências e habilidades são necessárias à profissão nesses tempos de novas condições e modalidades de trabalho (LIBÂNEO; OLIVEIRA; TOSCHI, 2011), emergindo novos padrões e modelos de formação de professores e suscitando a expansão da formação em contínuo, que vem atender à demanda imposta pela nova organização da sociedade que exige um determinado tipo de trabalhador com saberes essenciais. 
BOBATO, F. C. FERREIRA, P. D.

Diante do exposto, entendemos a necessidade de estudos aprofundados no que tange às políticas educacionais de formação continuada de professores no Brasil e também na América Latina, visto que os países latino-americanos foram e são alvos das diretrizes traçadas pelos organismos multilaterais aos países em desenvolvimento. 0 modo como se deram as reformas educacionais na América Latina e como elas alteraram as políticas de formação dos professores desperta a necessidade de compreender como essas relações se processam e se articulam nas propostas de formação continuada no Brasil e na Argentina.

Do ponto de vista metodológico, a pesquisa, que tem natureza qualitativa e tipo bibliográfico e documental, objetivou um estudo comparativo das políticas de formação continuada no Brasil e na Argentina a partir das reformas educativas da década de 1990.

Os achados da pesquisa apontam que: a formação continuada de professores é concebida como garantia das aprendizagens dos alunos; a formação em serviço é tema recorrente; a certificação é priorizada em detrimento de ampliação e aprofundamento de conhecimentos por parte dos professores; a ênfase na prática e, por fim, a infinidade de espaços e maneiras de oferta dessa formação, e quando dizemos isso, falamos do lócus (instituições de ensino superior, públicas e privadas, entidades empresariais, prefeituras, entre outras) e dos formatos dos cursos.

\section{CONSIDERAÇÕES INICIAIS}

As reformas educacionais postas em ação nos países da América Latina relacionam-se com a reestruturação do Estado e com a intensificação dos processos de globalização, tendo como pano de fundo o ideário neoliberal que atende "[...] ao projeto de um Estado que busca redirecionar a educação para os interesses de mercado, fazendo com que a regulação assuma o caráter central" (ENS; GISI, 2011, p. 29). Nesse sentido, a reforma dos Estados Nacionais, transferiu suas responsabilidades com o aparato público para a sociedade civil e possibilitou a entrada e a expansão do capital internacional.

Então, os diversos organismos internacionais como Banco Mundial (BM), Organização das Nações Unidas para a Educação, a Ciência e a Cultura (UNESCO), a Organização para a Cooperação e Desenvolvimento Econômico (OCDE) e Comissão Econômica para a América Latina e Caribe (Cepal) "direcionaram seu olhar para a educação em países da América Latina" (ENS; GISI, 2011, p. 28), recomendando e financiando políticas educacionais sob a justificativa de inseri-los na nova ordem econômica. Ou seja,

A influência da globalização nos sistemas educacionais se deriva tanto do aumento da competitividade econômica entre os países no nível mundial quanto da difusão de modelos culturais que defendem determinadas linhas de reforma educacional. Nesse aspecto, organismos como a OCDE ou o Banco Mundial cumpriram um papel significativo, recomendando ou prescrevendo políticas que enfatizam o papel da educação na provisão dos requisitos básicos para participar da nova 'economia do conhecimento' (GOROSTIAGA; VIEIRA, 2011, p. 64). 
Compreende-se que a intenção de modernização dos Estados Nacionais, bem como a sua inserção na corrida pelo capital, alterou significativamente o contexto educacional nos diversos países, em especial no contexto latino-americano. É certo que as reformas educacionais deflagradas nesse período colocaram em xeque os sistemas de ensino que passaram a ser vistos como "[...] obsoletos, pouco eficazes, de baixa qualidade e em desacordo com o que se esperava da escola para atender as necessidades e expectativas do século XXI" (BUENO et al., 2012, p. 1), o que fortalece a ideia de que as mudanças vivenciadas na sociedade estiveram a serviço da nova ordem econômica.

No que diz respeito aos países latino-americanos, praticamente todos estiveram à mercê das reformas que trouxeram impositivamente profundas alterações em suas leis gerais de educação, em que:

[...] as ações políticas adotadas nessa fase passam a enfatizar a necessidade de inovação das escolas, e de promoção de maior qualidade e equidade, na verdade, como novos discursos e estratégias para enfrentar antigos e persistentes problemas educacionais na região. Diferentemente de um passado não muito distante, em que as políticas colocavam ênfase sobre a modernização dos sistemas de ensino, as atuais reformas insistem na ideia de inovação. Competência, efetividade e descentralização passam a serem palavras-chave das propostas que são postas em prática desde então, cujas políticas alinham-se com o espírito da reforma do Estado, que desde os anos 1980 é fortemente orientada para e pelo mercado (BUENO et al., 2012, p. 2).

Outra vez, sob a égide de maior qualidade e equidade, competências, habilidades e formação, com ênfase na prática em detrimento da teoria, assumem o escopo das propostas. Velhos atores retornam a novos cenários. Mas, seriam mesmo novos cenários, ou então o retorno de tais atores? Não estariam se apresentando nos mesmos palcos e com uma nova roupagem apenas? Uma coisa é certa:

[...] longe de ser uma questão marginal, a educação encontra-se no cerne das proposições do Banco Mundial, como um requisito para a inexorável globalização, cumprindo a importante função ideológica de operar as contradições advindas da exclusão estrutural dos países periféricos que se aprofunda de modo inédito (LEHER, 1998, apudLIBÂNEO, 2016, p. 44).

Não obstante, no contexto pandêmico vivenciado mundialmente pela Covid19 , vemos constantes notícias sobre o dilema educativo em tempos de distanciamento social. As dificuldades se apresentam das mais variadas formas, seja pelo acesso aos ambientes virtuais, que acentua a desigualdade social, seja pelas possíveis práticas pedagógicas, pelo volume de trabalho docente ou pelas inúmeras queixas de incoerências nas atividades destinadas aos alunos. Tudo contribui para propostas 
BOBATO, F. C.; FERREIRA, P. D

imediatistas e interessadas, nas quais alguém ou um pequeno e seleto grupo sai lucrando de alguma forma.

Nas políticas de formação docente, em geral, propostas pontuais e descontínuas parecem ser uma tradição. É conveniente explicar que, embora tenhamos como objeto de estudo as políticas de formação continuada de professores, em alguns momentos do texto esbarramos nas políticas de formação inicial, uma vez que uma pressupõe a outra, além do que, ambos países intencionam propostas numa tentativa de articulação entre elas.

Antes de adentrarmos especificamente nas políticas de formação continuada nos países em tela, convém explicar o que entendemos por formação continuada de professores. É certo que sob o guarda-chuva (GATTI, 2008) do termo há distintos conceitos a depender de diferentes perspectivas teóricas, bem como inúmeros formatos de oferta deste momento de formação docente. Nesse sentido, diante de distintos conceitos, defendemos a formação continuada como um momento de formação para a ampliação e aprofundamento de conhecimentos, de maneira "[...] que busca emancipar o sujeito, pode ser individual ou coletiva, de forma voluntária, uma formação que estaria imersa no conceito de Educação Continuada" (DRI, 2013, p. 85), ou seja, formação ao longo da vida.

Sobre a formação continuada em serviço, é importante destacar que ela está fortemente vinculada à carreira docente, ou seja, é aquela “[...] oferecida aos profissionais da educação com vínculo empregatício, garantida por lei, na maioria dos casos, que impactam no emprego, na carreira do professor, na inovação e estão impressas nas políticas públicas educacionais" (DRI, 2013, p. 85). Nesse caso, a formação parte do princípio de que o saber fazer provém da própria prática docente, constituindose de momentos de reflexão da ação com vistas a modificá-la.

FORMAÇÃO CONTINUADA DE PROFESSORES NO BRASIL E NA ARGENTINA: POSSIBILIDADES DE REFLEXÃO

No Brasil, a lei geral da educação foi promulgada em 1996 e na Argentina em 1993, sendo substituída por outra mais recente em 2006. No caso brasileiro, a Lei de Diretrizes e Bases da Educação (LDB) n 9.394, de 20 de dezembro 1996, já recebeu inúmeras modificações via outros documentos de lei.

Sobre a formação continuada no Brasil, ela se deu principalmente com o intuito da profissionalização do docente e sua certificação em nível superior. No período histórico correspondente à promulgação da LDB 9.394/96, o país tinha boa parte de seus professores de educação infantil e anos iniciais do ensino fundamental formados apenas em nível médio. Isso estava evidente no artigo 87, § $4^{\circ}$ que dispunha: "Até o fim da Década da Educação somente serão admitidos professores habilitados em nível superior ou formados por treinamento em serviço" (BRASIL, 1996). Tal prerrogativa foi revogada pela lei no 12.796, de 2013.

Se por um lado o objetivo preconizado no $\S 4^{\circ}$ do artigo 87 tinha preocupação em elevar a formação do quadro do magistério, por outro desencadeou uma verdadeira corrida na ânsia de atender ao disposto. Dessa forma, muitas foram às fragilidades ocasionadas pelo aligeiramento da formação docente "[...] em nível superior em massa, dentro do menor espaço de tempo possível, aos docentes em serviço, constituiu a base 
de uma série de programas implantados em diversos estados e municípios do país" (KALMUS; SOUZA, 2016, p. 57).

Esse fato representou a expansão do sistema de formação continuada de professores, numa tentativa de formar essas massas em curto tempo. Bello (2008, p. 75) salienta que

O Brasil adotou, prioritariamente, por promover a certificação superior de seu quadro de professores da educação infantil e séries iniciais do ensino fundamental por meio de um modelo de formação em serviço organizado mediante a parceria entre instituições superiores de ensino (públicas e privadas), secretarias estaduais de educação e prefeituras. Foi ministrado por vários agentes educacionais (fragmentando-se, assim, as funções que tradicionalmente eram exercidas por uma só pessoa) e foi realizado normalmente fora do espaço universitário. É um modelo que se apoiou em apostilas padronizadas e foi oferecido em módulos, principalmente. Titulou uma grande massa de professores em um espaço de tempo inferior às graduações tradicionais e procurou utilizar recursos tecnológicos [...], ainda que muitas dessas intenções tecnológicas tenham ficado só no papel, dada a falta de recursos técnicos e financeiros.

É importante compreender que a formação confere ao professor a aquisição de bens culturais, e seu título de formação representa a forma institucionalizada de capital cultural, pois: "Ao conferir ao capital cultural possuído por determinado agente um reconhecimento institucional, o certificado escolar permite, além disso, a comparação entre os diplomados e, até mesmo, sua 'permuta' [...]' (BOURDIEU, 2015, p. 79).

Nesse sentido, o diploma ou certificado de formação é uma unidade de medida que possibilita medir e comparar os saberes incorporados pelos agentes, independente se de fato há apropriação desses saberes. Bourdieu $(2015$, p. 79) amplia essa discussão acrescentando que o título possuído possibilita também "[...] estabelecer taxas de convertibilidade entre o capital cultural e o capital econômico, garantindo o valor em dinheiro de determinado capital escolar".

O diploma ou certificado não representa de fato a aquisição de conhecimentos ao professor e, ao que revelam as políticas de formação, estão atrelados de certa maneira à manutenção do status quo. Assim,

As políticas educacionais sempre se referem a mudanças - mesmo
que por mudança queiramos dizer conter eventos suficientemente
de maneira a frear aquelas dinâmicas que poderiam, de outra forma,
mudar as coisas. Por exemplo, é provável que aqueles com
privilégios de classe social tentem e contenham grupos sociais que
poderiam organizar-se para criar mais oportunidades de mobilidade
social a partir das classes inferiores. As políticas educacionais
podem ser impulsionadas para assegurar que as coisas continuem
iguais. Em outras palavras, as políticas educacionais são voltadas 
BOBATO, F. C.; FERREIRA, P. D.

para re/organizar e re/ordenar as relações sociais por meio de estruturas e estratégias (ROBERTSON; DALE, 2017, p. 864).

Nessa perspectiva, sem dúvidas as políticas educacionais indicam mudanças, mas não mudanças com ganhos para toda a sociedade ou, pelo menos, para a sua maior parcela. Ao contrário, elas podem, sim, organizar-se para manutenção da ordem social vigente, ou para retrocessos retirando as poucas, morosas e penosas conquistas dos diferentes grupos sociais, como temos presenciado no Brasil nos últimos anos. Tais políticas, veladas ou escancaradas, estão à mercê de grupos de interesse compactuados nas relações de poder. Em outras palavras:

\begin{abstract}
Sempre que reconhecemos, na sociedade do presente, a luta ideológica de diferentes interesses, estamos olhando o presente com um olhar do tempo futuro. Para aqueles que projetam um futuro que repete as relações sociais do presente - em que são beneficiados e por isso mesmo impõem seus interesses como interesses de todos -, trata-se de entender a 'formação' como 'enformação', definindo desde sempre, e com o olhar voltado para o passado, como deve ser a forma do futuro. Trata-se de construir o futuro não como um acontecimento, mas como uma repetição do presente. Busca-se congelar os acasos para produzir/ construir subjetividades assujeitadas a um conjunto prefixado de modos de compreensão do mundo (COLLARES; MOYSÉS; GERALDI, 1999, p. 205).
\end{abstract}

As políticas de formação continuada no Brasil parecem atender bem a essa lógica, já que pouco modificam ou, no mínimo, parecem pouco agregar em termos de capital cultural ao professor, e numa perspectiva mais imediatista, às práticas escolares.

É certo que, com o advento da Educação a Distância (EAD) e a criação da Universidade Aberta do Brasil (UAB) em 2006, houve maior expansão da formação inicial, mas também da formação continuada. O uso das Tecnologias da Informação e Comunicação (TICs) favorece, especialmente na modalidade a distância, o acesso a um leque de oportunidades em termos de formatos de cursos. Desde então a EAD e o uso das TICs são extremamente estimulados no território nacional via inúmeras políticas. Nota-se que na Argentina, na prática, a modalidade a distância se deu tardiamente, embora fosse apontada pelos documentos; além disso, sua presença marca especificamente a formação continuada.

O Plano Nacional da Educação (PNE), aprovado pela Lei 13.005 de 2014, estabelece diretrizes, metas e estratégias para a política educacional no período de 2014 a 2024, tendo as Metas 15 e 16 como específicas para a formação docente. Na Meta 16, o PNE preconiza:

Formar, em nível de pós-graduação, 50\% (cinquenta por cento) dos professores da educação básica, até o último ano de vigência deste PNE, e garantir a todos (as) os (as) profissionais da educação básica formação continuada em sua área de atuação, considerando as necessidades, demandas e contextualizações dos sistemas de ensino (BRASIL, 2014).

Inter-Ação, Goiânia, v.46, n.1, p. 238-255, jan./mar. 2021. Disponível em: <http://dx.doi.org/10.5216/ia.v45i3.65176>. 
A concepção de formação continuada disposta pelo PNE (BRASIL, 2014) traz à baila o velho dilema acerca das diferentes formas de sua oferta, promovidas por distintos agentes educacionais, especialmente as fundações empresariais, cujas parcerias têm se fortalecido nos últimos anos. Além disso, retoma a formação em serviço no próprio local de trabalho. Ainda, considerando as Metas 15 e 16 do PNE (BRASIL, 2014), o Decreto 8.752 de 09 de maio de 2016 dispõe sobre a Política Nacional de Formação dos Profissionais da Educação Básica, concebendo no artigo 20:

\begin{abstract}
$\mathrm{VI}$ - a articulação entre formação inicial e formação continuada, e entre os níveis, as etapas e as modalidades de ensino;

VII - a formação inicial e continuada, entendidas como componentes essenciais à profissionalização, integrando-se ao cotidiano da instituição educativa e considerando os diferentes saberes e a experiência profissionais (BRASIL, 2016).
\end{abstract}

O texto enuncia a profissionalização enquanto fruto dos processos de formação inicial e continuada sem, contudo, explicitar de fato o significado deste conceito. Apoiadas em Shiroma e Evangelista (2011), asseveramos a necessidade da problematização de sua concepção e daquilo que está em seu bojo, para não incorrer no risco de, ao soar como positivo, mascarar seu real sentido, criando falsos consensos. Portanto, é um conceito a ser revisitado, pois:

Como 'qualidade, excelência, competência, eficácia e produtividade', essa noção ajuda a produzir consensos porque remete a uma valoração positiva, a um estado que todos almejam. Incluído no rol dos 'vocábulos positivos' que alicerçam o discurso reformador, o termo 'profissional' remete às noções de competências, credenciais, autoridade legitimada por um conhecimento específico e autonomia para exercer um ofício; remete a domínio de saber específico, próprio de um campo de atuação que requer formação específica em instituição credenciada, preferencialmente de nível superior. De outro lado, corresponde ao status de uma categoria que possui um código de ética, uma carreira, um plano de cargos e salários, um conselho que regulamenta, credencia e confere direito ao exercício profissional (SHIROMA; EVANGELISTA, 2011, p. 129).

Nos documentos nacionais mais recentes, a ideia de profissionalização docente está fortemente associada e articulada aos conceitos de competência e habilidade. Posterior à aprovação do PNE 2014-2024, tivemos a Resolução nº2 de maio de 2015 do Conselho Nacional de Educação (CNE), Conselho Pleno (CP) que dispunha acerca das Diretrizes Curriculares Nacionais para a Formação Inicial e Continuada dos Profissionais do Magistério da Educação Básica, revogada pela Resolução do CNE/CP n 2, de 20 de dezembro de 2019.

Embora entidades da área tenham se posicionado em defesa da Res. 02/2015, o CNE pelo CP, definiu as Diretrizes Curriculares Nacionais para a Formação Inicial de 
BOBATO, F. C.; FERREIRA, P. D.

Professores para a Educação Básica e instituiu a Base Nacional Comum para a Formação Inicial de Professores da Educação Básica (BNC-Formação), pela Resolução 02/2019.

Nas palavras dos próprios autores da BNC-Formação, ela é fundamental para que a implantação da Base Nacional Comum Curricular (BNCC) da Educação Básica seja realmente efetiva, pressupondo a dependência da aprendizagem dos alunos às competências dos professores. Ou seja, vinculando que "As aprendizagens essenciais, previstas na BNCC-Educação Básica, a serem garantidas aos estudantes, para o alcance do seu pleno desenvolvimento, [...] requerem o estabelecimento das pertinentes competências profissionais dos professores" (BRASIL, 2019).

O conceito de aprendizagens essenciais revela a necessidade de um determinado modelo de trabalhador, educado e/ou formado/conformado para a realização do básico e do essencial, enquanto que as competências profissionais dos professores demarcam o velho paradigma da racionalidade prática, ou seja, saber fazer. Isso tem a ver com mudar o trabalho do professor e o serprofessor (BALL, 2002). Embora a BNC-formação se refira especificamente à formação inicial, é mister apontá-la, já que atrelada a ela está a proposta para a formação continuada.

Em tempo, é importante e necessário destacar que o Brasil permanece aderindo aos postulados internacionais na continuidade de reformas de cunho neoliberal privatistas, implementando, nos últimos anos, reformas em todos os níveis educacionais e na formação docente. Prova disso, contrariando e excluindo qualquer contribuição de pesquisadores e entidades da área, bem como distante do debate público, o CNE dispôs e instituiu pela Resolução CNE/CP n ${ }^{\circ}$ 1, de 27 de outubro de 2020, Diretrizes Nacionais Curriculares e Base Nacional Comum da Formação Continuada de Professores da Educação Básica.

A professora Helena Costa Lopes de Freitas, na página Formação de Professores - Blog da Helena, no post publicado em 15 de julho de 2020, assevera que o documento referente às Diretrizes Nacionais Curriculares e Base Nacional Comum da Formação Continuada de Professores da Educação Básica:

[...] dá continuidade ao processo de regulação e maior controle da formação inicial (Cf. Res. 02/2019) e continuada, carreira e creditação de cursos e instituições, iniciado em 2017 no âmbito do MEC, como parte de um conjunto de normatizações que aprofundam a implementação de uma política de formação de professores de caráter tecnocrático, de maior controle sobre o trabalho pedagógico, alinhada exclusivamente às competências e conteúdos da BNCC e à lógica empresarial privatista que vem se impondo na educação básica pelos reformadores empresariais (FREITAS, 2020).

Tais diretrizes para a formação continuada dos professores da Educação Básica vêm reafirmar a lógica controladora e privatista imposta à educação no país e materializada pela via de um projeto reformador: Reforma do Ensino Médio, BNCC, BNC de Formação Inicial e Continuada. O que compreendemos desse movimento corporizado em reformas educacionais diz respeito a um projeto de sociedade em curso. Projeto este que é perverso e excludente, alimentado pela exclusão social estrutural e condições de extrema pobreza. 
Na Argentina as discussões acerca da formação continuada dos professores, de modo mais pontual, datam da década de 1980, tendo como destaque a criação do Instituto Nacional de Aperfeiçoamento e Atualização Docente (INPAD), "[...] com subsedes em todo o país e oferecia cursos a distância e presenciais, funcionou até 1992 quando se deu a transferência dos serviços educativos que estavam a cargo do ministério nacional de educação para as províncias [...]" (DRI, 2013, p. 129).

Sobre a transferência dos serviços educacionais da nação para as províncias, é importante observar que, assim como no Brasil, na década de 1990, a Argentina pôs em prática um processo de descentralização dos serviços educacionais. Assim, repassou às províncias à gestão, administração e financiamento das escolas primárias, secundárias e dos institutos de educação superior não universitários. No entanto, embora transferisse a responsabilidade de gestão e financiamento, manteve seu forte controle pela política educacional.

Em 1993, Lei Federal de Educação (LEF) n 24.295 foi promulgada como fruto de debates que vinham ocorrendo desde 1983 numa tentativa de democratização da educação, mas também como um pacote de medidas reformistas. O governo federal argentino teve importante participação na criação e organização das bases de seu sistema educativo. Para tanto, participou no

[...] financiamento da infraestrutura e aspectos voltados para a formação de professores, além de efetivar a transferência para as províncias da responsabilidade de oferta educativa e do desenvolvimento da formação docente nos diversos modelos, incluindo aqueles pautados nas experiências, para promover mudanças relacionadas ao domínio de conteúdos de ensino, enfatizando o discurso da descentralização (BUENO et al., 2012, p. $5)$.

Assim, a formação de professores argentinos esteve, em sua maior parte, sob a responsabilidade do Ministério da Cultura e Educação via Rede Federal de Formação Docente Contínua (RFFDC), que tinha como objetivo capacitar os professores em serviço com cursos oferecidos nas modalidades presenciais, semipresenciais e a distância. A maioria desses cursos ocorreu na modalidade presencial, realizados pelos governos provinciais "[...] que se ocupavam em avaliar a consistência, viabilidade e adequação das prioridades acordadas em relação aos planos apresentados pelas instituições, solicitando, quando necessário, ajustes e adequações" (BUENO et al., 2012, p. 6). É sabido que a RFFDC fomentou:

[...] um mercado de capacitação até então inédito na Argentina (Gentili y Suárez, 2005). Entre as principais instituições oferentes destacam-se os Institutos de Formação Docente (IFD) públicos e particulares (inclusive os religiosos), sindicatos e Organizações Não Governamentais, focalizando a formação superior não universitária; as universidades participaram pouco deste processo, principalmente pelos focos de resistência política (BUENO et al., 2012, p. 6). 
BOBATO, F. C.; FERREIRA, P. D.

No que se refere aos cursos da RFFDC, esses foram se enfraquecendo, pois, as demandas da escola não poderiam ser resolvidas ou amenizadas apenas com conteúdos, mas, sim, com uma compreensão maior acerca das questões sociais (BUENO et al., 2012). Em 2006 uma nova lei geral da educação foi aprovada na Argentina, a Lei da Educação Nacional (LEN) n²6.206, trazendo inúmeros avanços ao setor.

A partir dela, em 2007, foi criado o Instituto Nacional de Formação de Professores (INFoD), que representou um marco na formação de professores, tendo como atribuição o planejamento das ações políticas de formação continuada e desenvolvimento profissional considerando a formação inicial e continuada como processos articulados. Desde então o INFoD tem se organizado no sentido de propor ações para a formação docente.

O Plano Nacional de Formação Docente 2016-2021 explica que, tradicionalmente, os cursos de formação continuada, em geral, são curtos, assistemáticos, isolados e fora dos seus ambientes de trabalho, o que reflete num modelo de sobreposição e dispersão da formação (ARGENTINA, 2016). Embora, existam outros formatos de curso na tentativa de superar tais características, essas ainda são insuficientes para dirimir a falta de articulação desses cursos com a prática pedagógica, resultando em pouco impacto na melhoria de ensino (AGENTINA, 2016).

Nessa linha, as ações têm se orientado em propostas formativas pautadas na prática docente, no compartilhamento e troca de experiências e no estudo e resolução de situações concretas, numa tentativa de articulação com a prática pedagógica. Além disso, os percursos formativos têm uma duração maior, como é o caso da formação situada que prevê dois percursos com duração de três anos cada uma.

Posto isso, o INFoD se propõe a: a) Potencializar a formação situada; b) Promover a formação de supervisores e diretores; c) Oferecer instâncias de formação especializada; d) Fortalecer a institucionalização da formação continuada e sua articulação com a carreira docente.

Considerando os pressupostos legais para a formação continuada e o reconhecimento da LEN n 26.206/06, artigo 67, sobre o direito de todos os docentes do sistema educativo: "A capacitação e atualização integral, gratuita e em serviço, ao longo de toda sua carreira" (ARGENTINA, 2006), o CFE aprovou, pela Resolução n 316 de 2017, o Plano de Ação 2017-2021 do Programa Nacional de Formação Permanente ${ }^{1}$ (PNFP) Nuestra Escuela.

Dentre as intenções do Plano de Ação do PNFP Nuestra Escuela anexo à Resolução 316/17, destacamos a Formação Docente Situada (FDS), que propõe a formação em exercício contemplando "[...] os contextos e necessidades específicas de cada escola" (ARGENTINA, 2017, p. 6); e a Formação Docente Especializada (FDE) que "é uma estratégia de formação orientada a aprofundar temas e ações metodológicas consideradas chave para enfrentar os desafios do processo de ensino" (ARGENTINA, 2017, p. 11).

O Observatório de Práticas Educativas (OPE) é uma iniciativa do INFoD "[...] cujo principal objetivo é colocar à disposição do sistema formativo quadros de reflexão, análise e produção de saberes acerca da formação docente e do processo de ensino" (INFOD, 2020), ou seja, reflexão sobre a prática. Nesse aspecto, o OPE tem como perspectiva o Desenvolvimento Profissional Docente conforme postulado na Resolução n 30/2007 do Conselho Federal de Educação: 


\begin{abstract}
Um princípio fundamental presente na ideia de desenvolvimento profissional docente é o trabalho horizontal e colaborativo entre formadores, especialistas e docentes, o que leva a revalorização dos saberes da ação e os princípios construídos através da experiência. Este enfoque também recebe o nome de 'conhecimento da prática' porque propõe a investigação como atitude permanente e não divide o universo do saber em teoria de um lado, e a prática de outro. Através de seu desenvolvimento profissional, o docente identifica, levanta e busca soluções para os problemas de sua prática (ARGENTINA, 2007, p. 7).
\end{abstract}

A Argentina vivencia ainda uma realidade, em termos de formação continuada, que está relacionada à soma de pontos para ascender na carreira. Ou seja, essas qualificações "[...] não promovem uma tendência a formação docente mais profunda e de longa reflexão, porém geram uma tendência a cursos variados, de todos os tipos e, muitas vezes, distantes da prática laboral dos docentes, mas que outorgam pontos para a carreira" (DRI, 2013, p. 120).

Tradicionalmente, a Argentina apresenta, como dilema ao processo formativo continuado, as questões relacionadas à formação articulada com as questões da prática docente. Estudar a prática docente a partir das questões que emergem da própria escola, enquanto lócus formativo, é uma discussão posta por diversos pesquisadores. Contudo, por mais que essa prática dê conta das especificidades de cada escola, certamente cairá no esvaziamento se desconsiderar os contextos em que esta escola está inserida. Além disso, é preciso compreender que os contextos políticos, sociais, culturais e econômicos estão permeados pelas relações de poder, constituindo uma arena de disputa em que interesses se misturam e contrapõem.

As discussões acerca da formação continuada de professores vistas nas últimas três décadas revelam que velhos dilemas e discursos são recorrentes em ambos os países. Os debates acerca da práxis pedagógica parecem pertencer ao mundo dos debates apenas, uma vez que os documentos enfatizam a centralidade na prática, justificando que a teoria está muito distante das situações concretas da escola.

O processo de formação docente, enquanto formação humana, pressupõe um profundo e constante conhecimento sobre o homem (SAVIANI, DUARTE, 2012). Nesse sentido, a formação ao longo da carreira docente requer conhecimentos teóricos e práticos como processos relacionados e indissociáveis. Pois,

Ao isolar a teoria da prática ou a prática da teoria, o homem é
destituído de sua capacidade de agir de forma consciente, é
impossibilitado de compreender os condicionamentos que o
determinam, é privado da possibilidade de (re) construir sua
realidade. Ao isolar a teoria da prática ou a prática da teoria, os
processos de formação abalam a capacidade do educador de
pensar sobre a ação pedagógica, de compreender a estrutura da
escola, de aclarar os propósitos da educação, de elucidar as formas
de existência e de organização social, em toda sua complexidade e 
BOBATO, F. C.; FERREIRA, P. D

historicidade e [...] de recriá-las, de transformá-las, de superá-las (SOUZA, 2001, p. 7).

Ou seja, teoria e prática dicotomizadas oferecem ao professor uma visão parcial, reduzida e até mesmo esvaziada do processo educacional e social. Outro aspecto importante se refere à formação em serviço complementando a ideia de formação prática, além da possibilidade de preencher lacunas e déficits na formação inicial, cujos projetos também direcionam seu esvaziamento teórico.

Com cursos de formação inicial e continuada vazios do ponto vista teórico, os certificados funcionam como passaportes para elevação na carreira, sem representar qualquer ascensão em termos de conhecimentos e reflexões mais aprofundadas. Assim, é dado ao professor apenas o essencial para saber fazer algo, para operar a técnica, aplicar a receita.

Por fim, os documentos legais fomentam inúmeras possibilidades de ofertas da formação continuada, que se apresentam de diferentes formatos, em modalidades presenciais, semipresenciais e a distância, e que estão, principalmente, nas mãos da iniciativa privada. Um verdadeiro mercado movimentado por dinheiro público.

É interessante observar que, sob o discurso da formação continuada de professores com o intuito de melhorar os processos de ensino e aprendizagem, ampliando sua qualidade, há uma lógica contrária que exerce controle sobre os processos e que se mostra perversa a partir do momento que precariza a docência. Além disso, essa lógica produz consensos acerca do professor e do seu trabalho, isto é, reduz o professor a um mero reprodutor de informações, cujo trabalho é qualificado pelo saber fazer em detrimento de toda complexidade do trabalho docente.

\section{PALAVRAS FINAIS}

Sempre que nos ocupamos do estudo das políticas educacionais percebemos o quanto a tarefa é desafiadora. Em tempos de conservadorismo exacerbado, as discussões no âmbito popular e das próprias áreas de interesse têm sido ignoradas, especialmente nas práticas recentes do Ministério e do Conselho Nacional da Educação no Brasil.

O entendimento de que a formação do professor garante a melhoria das aprendizagens dos alunos é recorrente nas políticas brasileiras e argentinas desde as reformas iniciadas na década de 1990. Embora tais países tenham trilhado caminhos distintos em determinados aspectos da organização e implementação de suas políticas educativas, ambos atenderam aos pressupostos dos organismos internacionais e adotaram seus conceitos e modos de conceber a docência e o fazer pedagógico.

Nessa direção, as considerações de alguns aportes teóricos apontados neste ensaio convidam a uma ampliação de nosso olhar sobre o desafio da formação continuada de professores. Não podem estar ausentes dessa tarefa a análise crítica das propostas de reformas educacionais nem a valorização do saber do professor, que é fruto da sua prática docente cotidiana e de seus percursos formativos realizados de forma autônoma na perspectiva da práxis. 


\section{COMPARATIVE STUDY OF CONTINUOUS TRAINING POLICIES FOR TEACHERS: POSSIBLE REFLECTIONS FROM BRAZIL AND ARGENTINA}

ABSTRACT: The present article had as scope a comparative study of the continuing teacher education policies in Brazil and Argentina. Based on bibliographic and documentary research, we rehearsed possible reflections on the policies of these countries, aligned or not with the international organisms postulates. In view of the research findings, we concluded that both countries met these postulates, adopting their concepts and ways of conceive the teaching and the pedagogic action. In the list of texts studied about the continuing teachers education, we can highlight that: it appears as a guarantee for improving learning students; there is recurrence for inservice training; certification to the detriment of real situations of expansion and deepening knowledge; the multiple spaces and offers of this training, especially by the private sector, and the emphasis on know-how.

KEYWORDS: Continuing Teacher Education Policies. Teaching Work. Educational Reforms. International Organisms. Brazil and Argentina.

ESTUDIO COMPARATIVO DE LAS POLITICAS DE FORMACIÓN CONTINUA PARA PROFESORES: POSIBLES REFLEXIONES DESDE BRASIL Y ARGENTINA

RESUMEN: El presente artículo tuvo como alcance un estudio comparativo de las políticas de formación continua de docentes en Brasil y Argentina. A partir de una investigación bibliográfica y documental, probamos posibles reflexiones acerca de las políticas de estos países, alineadas o no con los postulados de los organismos internacionales. A la vista de los hallazgos de la investigación, concluimos que ambos países cumplieron con estos postulados, adoptando sus conceptos y formas de concebir la docencia y la acción pedagógico. En la lista de textos estudiados acerca de la formación continua de los profesores, podemos destacar que: ello aparece como garantía para la mejora del aprendizaje de los estudiantes; hay recurrencia para la formación en servicio; certificación en detrimento de situaciones reales de ampliación y profundización del conocimiento; los múltiples espacios y ofertas de esta formación, especialmente por parte del sector privado y el énfasis en el saber hacer.

PALABRAS CLAVE: Políticas de Formación Continua del Profesorado. Trabajo Docente. Reformas Educacionales. Organismos Internacionales. Brasil y Argentina.

NOTA

Inter-Ação, Goiânia, v.46, n.1, p. 238-255, jan./mar. 2021. Disponível em: <http://dx.doi.org/10.5216/ia.v45i3.65176>. 
BOBATO, F. C.; FERREIRA, P. D

1 - O Programa Nacional de Formação Permanente foi aprovado pelo Conselho Federal de Educação argentino pela Resolução n 201 de 21 de agosto de 2013, tendo por base a Lei da Educação Nacional (LEN) n 26.206 de 2006 e a Resolução do CFE n 188 de 5 de dezembro de 2012, que aprovou o Plano Nacional de Educação Obrigatória e Formação Docente 2012 - 2016.

\section{REFERÊNCIAS}

ARGENTINA. Consejo Federal de Educación. Anexo Resolución CFE n. 316/2017. Programa Nacional de Formación Permanente Nuestra Escuela. Plan de acción 20172021. Ciudad Autónoma de Buenos Aires: 2017.

ARGENTINA. Ministerio de Educación y Deportes. Instituto Nacional de Formação Docente. Plan Nacional de Formación Docente 2016-2021. Ciudad Autónoma de Buenos Aires: 2016.

ARGENTINA. Resolución CFE n³0 de 29 de noviembre de 2007. Ciudad Autónoma de Buenos Aires: 2007.

ARGENTINA. Ley de Educación Nacional n²6.206 de 14 de deciembre de 2006. Ciudad Autónoma de Buenos Aires: 2006. Disponível em: https://www.argentina.gob.ar/sites/default/files/ley-de-educ-nac-58ac89392ea4c.pdf. Acesso em: 20 mai. 2020.

BALL, S. J. Intelectuais ou técnicos? O papel indispensável da teoria nos estudos educacionais. In: BALL, S. J.; MAINARDES, J., (orgs.). Políticas Educacionais: questões e dilemas. São Paulo: Cortez, 2011. p. 78-99.

BOURDIEU, P. Escritos de educação. Organização: Maria Alice Nogueira e Afrânio Catani, Petrópolis, RJ: Vozes, 2015.

BELLO, I. M. Formação superior de professores em serviço: um estudo sobre o processo de certificação do magistério no Brasil. 2008. Tese (Doutorado em Educação) Faculdade de Educação. Universidade de São Paulo, São Paulo, 2008.

BRASIL. Ministério da Educação. Resolução CNE/CP n² 2, de 20 de dezembro de 2019. Define as Diretrizes Curriculares Nacionais para a Formação Inicial de Professores para a Educação Básica e institui a Base Nacional Comum para a Formação Inicial de Professores da Educação Básica (BNC-Formação). Brasília: DF, 2019.

BRASIL. Decreto 8.752/2016 de 09 de maio de 2016. Dispõe sobre a Política Nacional de Formação dos Profissionais da Educação Básica. Brasília: DF, 2016.

BRASIL. Lei no 13.005 de 25 de junho de 2014. Aprova do Plano Nacional da Educação. Brasília: DF, 2014. Disponível em: http://pne.mec.gov.br/18-planos-subnacionais-de- 
educacao/543-plano-nacional-de-educacao-lei-n-13-005-2014. Acesso em: 29 jul. 2020.

BRASIL. Ministério da Educação. Lei de Diretrizes e Bases da Educação Nacional. Lei nº 9394, de 20 de dezembro de 1996. Estabelece as diretrizes e bases da educação nacional. Brasília: DF, 1996.

BUENO, B. O. Formação continuada de professores na América Latina: as políticas do Chile, México e Argentina. In: Seminario internacional de La Red Estrado. Políticas educativas para América Latina: praxis docente y transformación social, 9., 2012, Santiago de Chile. Anais... Santiago de Chile: s. n., 2012. CD-ROM.

COLLARES, C. A. L.; MOYSÉS, M. Apa. A.; GERALDI, J. W. Educação Continuada: a política da descontinuidade. Educação e Sociedade [online], Campinas, v. 20, n. 68, p. 202 2019, dez., 1999. Disponível em: https://www.scielo.br/scielo.php?pid=S010173301999000300011\&script=sci_abstract\&tlng=pt. Acesso em: 07 ago. 2020.

DRI, W. I. de O. A ação pública e a formação continuada de professores: um estudo de caso no Brasil e na Argentina. 2013. Dissertação (Mestrado em Educação) - Faculdade de Educação, Universidade Estadual de Campinas, Campinas, 2013.

ENS, R. T.; GISI, M. L. Políticas Educacionais no Brasil e a Formação de Professores. In: ENS, R. T.; BEHRENS, M. Apa (Orgs). Políticas de Formação do Professor: caminhos e perspectivas. Curitiba: Champagnat, 2011.

FREITAS, H. C. L. de. A portas fechadas, DCN e BNC da Formação Continuada são aprovadas pelo CNE. Formação de Professores - Blog da Helena, 2020. Disponível em: https://formacaoprofessor.com/2020/07/15/a-portas-fechadas-dcn-e-bnc-da-formacaocontinuada-sao-aprovadas-pelo-cne/. Acesso em: 14 ago. 2020.

GATTI, B.A. Análise das políticas públicas para formação continuada no Brasil, na última década. Revista Brasileira de Educação, v. 13, n. 37, p. 57-70, jan./abr. 2008.

GOROSTIAGA, J. M.; VIEIRA, L. M. F. Tendências nacionais e subnacionais no governo escolar: Argentina e Brasil, 1990-2010. In: OLIVEIRA, D. A.; PINI, M. E.; FELDFEBER, M. (orgs). Políticas Educacionais e trabalho docente: perspectiva comparada. Belo Horizonte: Fino traço, 2011. p. 63-90.

INFOD. Observatorio de Prácticas Educativas. Instituto Nacional de Formación Docente, 2020. Disponível em: https://red.infd.edu.ar/observatorio-de-practicaseducativas/. Acesso em: 09 ago. 2020.

KALMUS, J.; SOUZA, M. P. R. de. Trabalho e Formação: uma análise comparativa das políticas de formação de professores em serviço no Brasil e no México. Educação e Pesquisa [online], São Paulo, v. 41, n.1, p. 53-66, jan./mar. 2016. 
BOBATO, F. C.; FERREIRA, P. D

LIBÂNEO, J. C. Políticas educacionais no Brasil: desfiguramento da escola e do conhecimento escolar. Cadernos de Pesquisa [online], São Paulo, v.46, n.159, p. 38-62, jan./mar. 2016. Disponível em: https://www.scielo.br/scielo.php?pid=s010015742016000100038\&script=sci_abstract\&tlng=pt. Acesso em: 20 mai. 2020.

LIBÂNEO, J. C.; OLIVEIRA, J. F. de; TOSCHI, M. S. Educação Escolar: políticas, estrutura e organização. 10. ed. São Paulo: Cortez, 2011.

MARTINEZ, F. W. Um campo de disputa: a formação inicial dos professores de ciências biológicas. In: TOZETTO, S. S.; LAROCCA, P. Desafios da formação de professores: saberes, políticas e trabalho docente. Curitiba: CRV, 2014. p. 55-68.

ROBERTSON, S.; DALE, R. Comparando Políticas em um Mundo em Globalização: reflexões metodológicas. Educação e Realidade, Rio Grande do Sul, v. 42, n. 3, p. 859-876, jul./set. 2017.

SAVIANI, D.; DUARTE, N. A formação humana na perspectiva histórico-ontológica. In: SAVIANI, D.; DUARTE, N. (Orgs). Pedagogia histórico-crítica e a luta de classes na educação escolar. São Paulo: Autores Associados, 2012. p. 13-36.

SHIROMA, E. O.; EVANGELISTA, O. Avaliação e responsabilização pelos resultados: atualizações nas formas de gestão de professores. Perspectiva, Florianópolis, v. 29, n. 1, p. 127-160, jan./jun. 2011.

SOUZA, N. A. de. A relação teoria-prática na formação do educador. Semina: Ciências Sociais e Humanas, Londrina, v. 22, p. 5-12, set. 2001.

Francine Cordeiro Bobato: Professora colaboradora do curso de Pedagogia da Universidade Estadual do Centro-Oeste (UNICENTRO). Doutoranda em Educação pela Pontifícia Universidade Católica do Paraná (PUC-PR). Mestre em Educação pela Universidade Estadual do Centro-Oeste (UNICENTRO). Graduada em Pedagogia pela Universidade Estadual de Ponta-Grossa (UEPG). Atua e desenvolve pesquisas em políticas educacionais, formação de professores, sestão educacional, educação internacional, educação comparada e ensino médio e juventudes. Membro dos grupos de pesquisa: História e políticas da educação: formação de professores - PUCPR; Educação e formação de professores - Unicentro; Práxis educativa: saberes e fazeres da/na educação infantil - Unicentro; Estado, políticas e gestão em educação - Unicentro. Núcleo de Estudos e Pesquisas sobre Ensino Médio e Juventudes - NEPEMJ - IFPR.

Orcid: https://orcid.org/0000-0002-7466-9589

E-mail: francbto@gmail.com;

Paloma Domingues Ferreira: Possui graduação em Pedagogia pela Universidade Estadual do Centro-Oeste (2017). Mestre em Educação pela mesma instituição, bolsista Capes. Especialista em Neuropsicopedagogia; Atendimento Educacional Especializado 
com Ênfase em Educação Especial e Inclusiva; e, Gestão Educacional: Direção, Coordenação e Supervisão; pela União Brasileira de Faculdades- UniBF. Especialista em Docência no Ensino Superior pela Universidade São Luís. Professora da Escola Municipal Rosalina Cordeiro Araújo - Educação Infantil e Ensino Fundamental, Irati - PR. Atua e desenvolve pesquisa em políticas educacionais, formação de professores, formação de professores em contextos inclusivos, educação internacional e educação comparada. Integrante dos grupos de pesquisa: Formação Profissional em Contextos Educacionais Inclusivos - FOCUS - Unicentro; Estado, políticas e gestão em educação - EPGE Unicentro.

Orcid: https://orcid.org/0000-0003-2449-3877

E-mail: paloma.ferreira12@hotmail.com

Este periódico utiliza a licença Creative Commons Attribution 3.0, para periódicos de acesso aberto (Open Archives Iniciative - OAI). 